\title{
THE CONTEMPORARY LIFE OF THE AETAS OF STA. ANA, CAGAYAN, PHILIPPINES THROUGH PARTICIPATORY- PHOTOGRAPHY APPROACH
}

\author{
Janelyn V. ANCHETA \\ University of Saint Louis, Philippines \\ Jolina V. PELOVELLO \\ University of Saint Louis, Philippines \\ Coleen P. ROMERO \\ University of Saint Louis, Philippines \\ Reden L. DELOS SANTOS \\ University of Saint Louis, Philippines \\ Karl Leonivd S. GANNABAN \\ University of Saint Louis, Philippines \\ Darin Jan C. Tindowen, MARE \\ University of Saint Louis, Philippines
}

(C) The Author(s) 2017

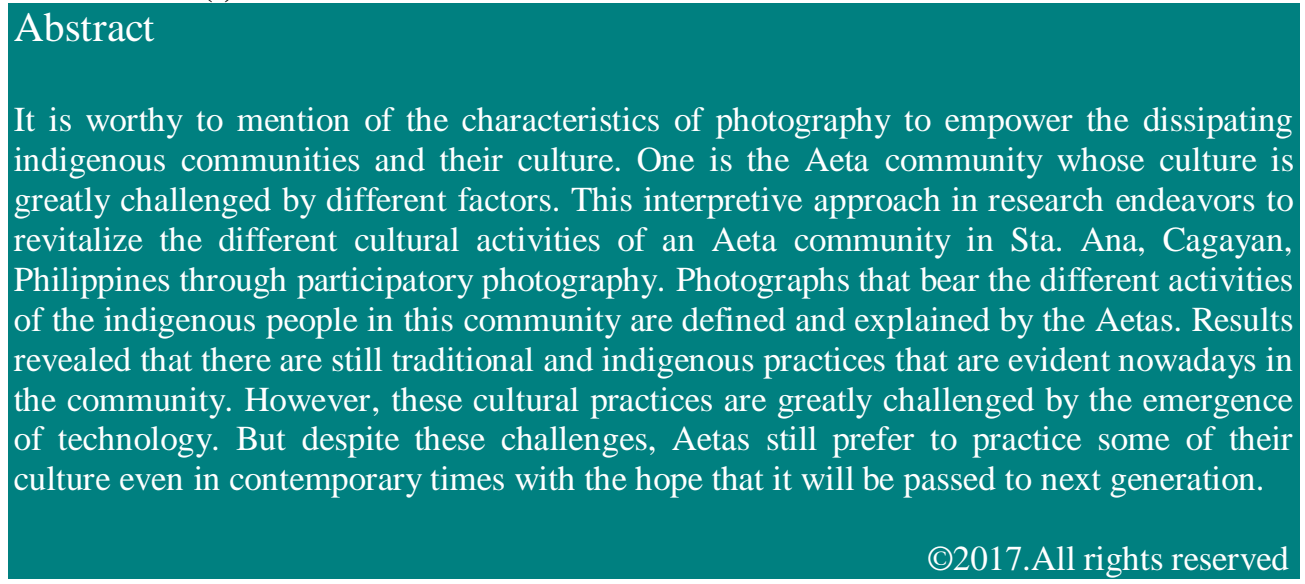

\section{ARTICLE HISTORY}

Received: 14/03/2017

Accepted: 09/08/2017

Published online: 05/10/2017

\section{KEYWORDS}

Participatory photography, Aeta

Community, Contemporary life

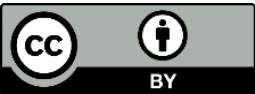




\section{Introduction}

The Philippines is a home to different ethnic and indigenous communities. As a matter of fact, there are around 14-17 million Indigenous Peoples (IP) that belong to 110 ethno- linguistic groups which are mainly concentrated in Northern Luzon (33\%) and in Mindanao (33\%), with some groups in the Visayas, Southern and Western Luzon, Palawan and in Sulu archipelago (United Nations Development Programme, 2010). Among the different ethnic and indigenous groups in the country, the Negritos or in some communities are known as Aetas or Aetas are considered as a major indigenous group since they are scattered across the different parts of the country (Ocampo \& Ocampo, 2014). At present, the Negrito population is roughly 90,000 and divided into 25 ethno linguistic groups dispersed in bands from Luzon to Mindanao. The most numerous are those found in the islands of Luzon (Molintas, 2004), such as in the province of Cagayan, a home to a great number of Aetas who are considered as the first inhabitants of the province. However, because of their nomadic character in seeking for their food and survival, they later moved to the uplands and some settled in the far flung areas (Hortelano, Juan, \& Tindowen, 2015). And today, most of them are found in forested hills on the remote parts of the municipal areas of Pamplona, Sta Ana, Gonzaga, Gattaran, and Penablanca (Tindowen, 2016).

With the emergence of information technology and globalization, many changes happened in every society. However, it is also important to note that previous studies had revealed cultural change to many indigenous communities in the world (Brown, 2008) especially in terms of the ability of these groups in preserving and retaining their cultural practices and indigenous knowledge (Dyson \& Underwood, 2006; Azarya, 2004; Bowannie, 2009; Lydon, 2014; Sandweiss, 2004). And this is true to indigenous groups in the Philippines (Tindowen, 2016; Todd, 2003).

With this challenge being faced by the different indigenous groups, many studies affirmed that information technology and globalization may also be used as a tool for the preservation and retention of the different indigenous knowledge and practices (Munro, 2008; Ketelle, 2010; Dingley, 2001; Jennings \& Lowe, 2013) such as the use of photography (Bananuka \& John, 2014; Martin, 2013; Bardis, 2004; Gigler, 2008). Photography, by far, remains a medium to retain memories in 
the past and provide tangible material for the present and the future (Harpar, 1994; Harrison, 2002; Johnson, 1998; Lavallee, 2009) and can be associated to the documentation of the real-life that includes people and their ways of living (Nickel, 2001; Wrigh, 2004). It is worthy to mention that one of the characteristics of photography is to empower the dissipating indigenous communities (Strathman, 2013; Kim, 2010; Keller, 2008; Bolter, Grusin, \& Grusin, 2000) whose culture and traditions is greatly challenged by the global emergence of advanced technologies. Hence, this study is conducted to document the contemporary life of the Aetas of Nangaramoan, Sta. Ana, Cagayan, Philippines.

\section{Methods}

This interpretive approach in research utilized participatory photography in order to document the contemporary lifestyle of the Aeta community specifically in Nangaramoan, Sta. Ana, Cagayan. Participatory photography is a method in which participants become the authors of their own photographs, and have opportunities to represent their experiences of the phenomenon under study (Castleden \& Garvin, 2008; Coles-Ritchie, Marilee, Monson, \& Moses, 2015; Higgins, 2014). Further, this method is used to empower marginalized groups to depict their experiences through visual images (Cuevas-Wolf, 1998; Fischer-Olson, 2004; Halvaksz, 2008; Herr, 2014).

This study was conducted in Nangaramoan, Sta. Ana, Cagayan, a place reputed to house enchanting beaches that entice local and foreign tourists. The Aetas in Nangaramoan, Sta. Ana, Cagayan took part in the generation of the pieces of information necessary to complete this study. Digital cameras were used as instruments necessary in documenting and gathering pieces of information about the contemporary lifestyle of the Aeta people. Photographs were not only taken, but an oral interview with the indigenous people has greatly contributed in the better understanding of whom and what they really are. The results of the interview and how photographs are perceived by the Aetas were scholastically organized into paragraphs.

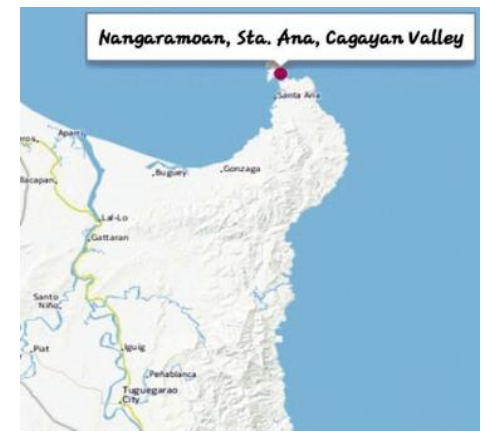


The contemporary lifestyle of the Aetas, specifically in Nangaramoan, Sta. Ana, Cagayan was observed with the help of photography. In this regard, photographs were explained by the Aeta people in the community and were analysed in a manner which is objective. Further, the researchers have employed the ethical considerations in photography and journalism which objectively present realities in a manner not vain and ineffectual. This qualitative research is anchored in the neutrality of pictorial reportage. Imbued with the formalities of conducting research, proper seeking of permission to the immediate authority in the community was observed.

\section{Results}

\section{Background of Aetas in Sta. Ana, Cagayan}

Known for the enchanting and aesthetics of Nangaramoan Beach in the municipality of Sta. Ana, Cagayan, vacant land areas are now inhabited by Aeta people from various Aeta communities in the province like Gattaran and Penablanca in search for living.

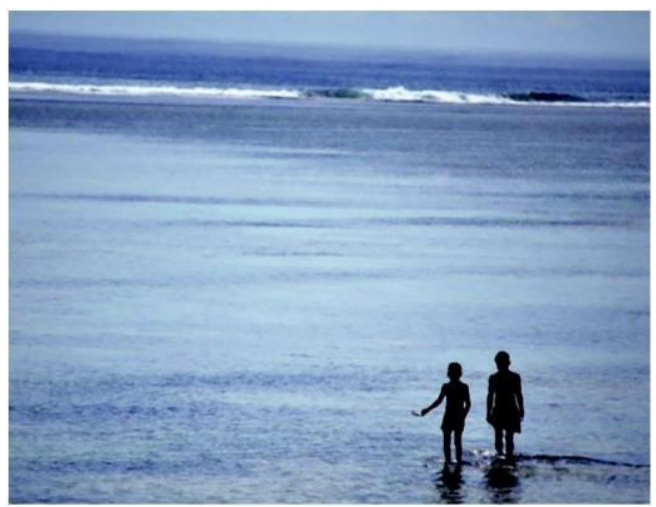

But long before that, a history of an Aeta community can be traced from the earlier times of Nangaramoan before it was discovered as a tourist spot. It sheltered an ethnic group of Aetas, the first to occupy the place. Nangaramoan was then an area of thick forest until its discovery and the coming of industrialization. Roads from Poblacion leading to the beaches were made, cottages were built and electricity and water were installed; these have tourism industry of Nangaramoan and other beaches. 
The original group of Aetas produced by their early generation has remained. And at the emergence of businesses in the place, varied groups of Aetas did find their place to occupy in search of livelihood or chances of earning in simple ways from tourists that come; from there they have raised their families.

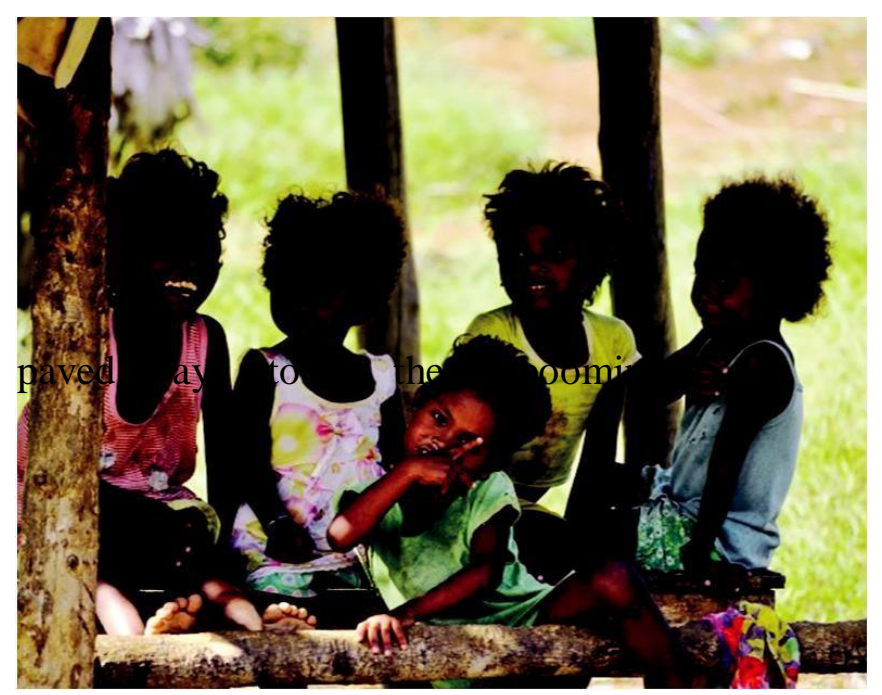

At present, the community has 12 households which are mainly dominated by toddlers. Their coming in Nangaramoan resonates their being nomads who walk the terrestrials in order to live.
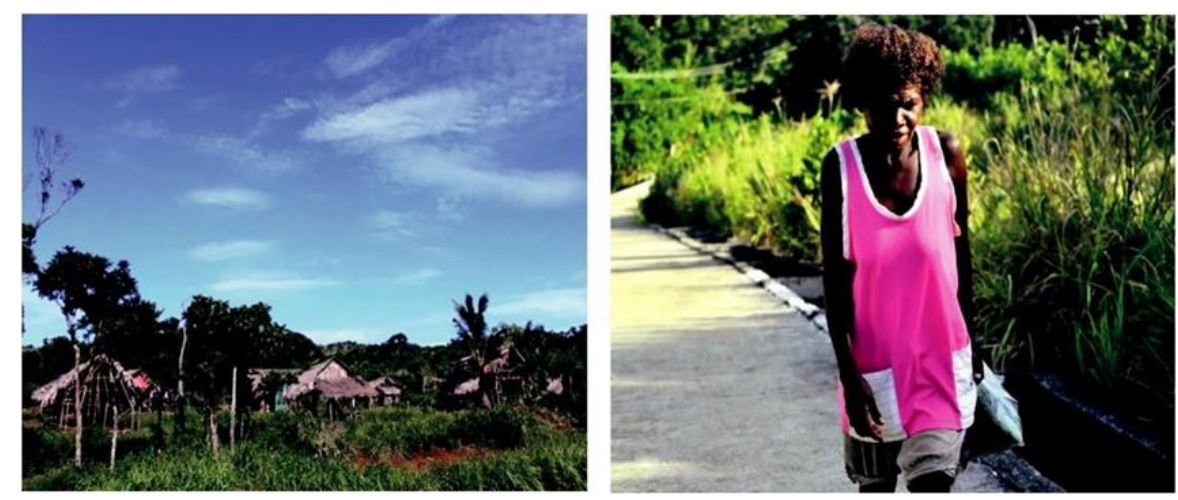

Int.J. Hum. Soc. Dev. Res.

Volume 1, № 2, 2017.35-52 


\section{Concept of Territoriality}

The group of Aetas in Sta. Ana occupied an area on a hilltop connected in Sierra Madre. In the province's geography, it is situated in the northeastern tip facing the direction to the Batanes group of islands in the north and the Pacific Ocean in the east.Their area is a gateway to Pozo Robo (east) and Nangaramoan (north) beach just beside the concrete road constructed at the advent of tourism industry in Sta. Ana.In the current state, their community is facing issue regarding the land ownership. Unknown individuals sent by a politician have fenced their area with barb wires and concrete posts blocking their way in and out.

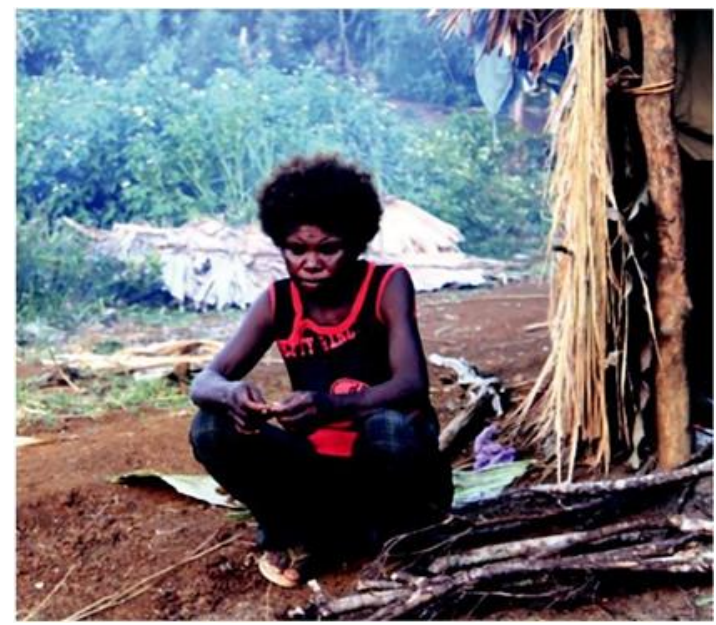

\section{Concept of Identity}

Their group is no different to Aetas around the province. Since they are comprised of groups from Gattaran and Penablanca, they share the same identity. They are still those that have kinky hair, dark skin tone and short in height. Their identity is traced as familiar to the early settlers in the Philippines, the Borneos.

Moreover, they are usually seen in mountainous area. Their houses are mainly made of - Anahawll leaves, high rise grasses wherein those materials are already available in the mountain. They prefer to have this type of houses because it is easy to build and transfer. This manifests their being nomadic in nature. 
Aside from using - Ilocanoll language they also have their own language, but nobody knows or understands it. Lowlanders often look down on them, who have lived in the upland areas. Because of this, they are sometimes considered as uncivilized having bad manners, ugly and ignorant. Because of this discrimination, they have often tried to blend into contemporary society, in the process of losing their own identity.

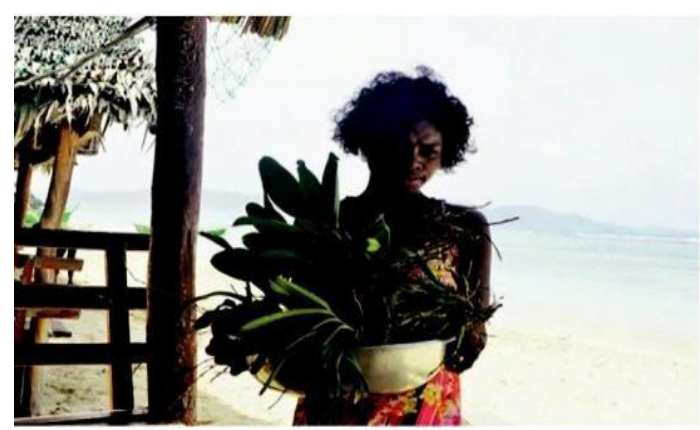

\section{Economic Activities and Sources of Livelihood}

Known for their being - Walkers of Earthll, the Aetas are resolute to finding ways so that they will live. Most of the elders did not enter school but that did not impede them to be good breadwinners of their respective families. As their location is near to the sea, fishing is the leading activity in their community. The richness of the sea serves now as the springboard of their economy. Caught fishes are being sold to nearby establishments especially those in the beaches. With the gift again of nature, Aetas harvest wild orchids of different species that grow in a diverse forest. It takes them a 5-hour walk to get into the place where orchids are abundant.
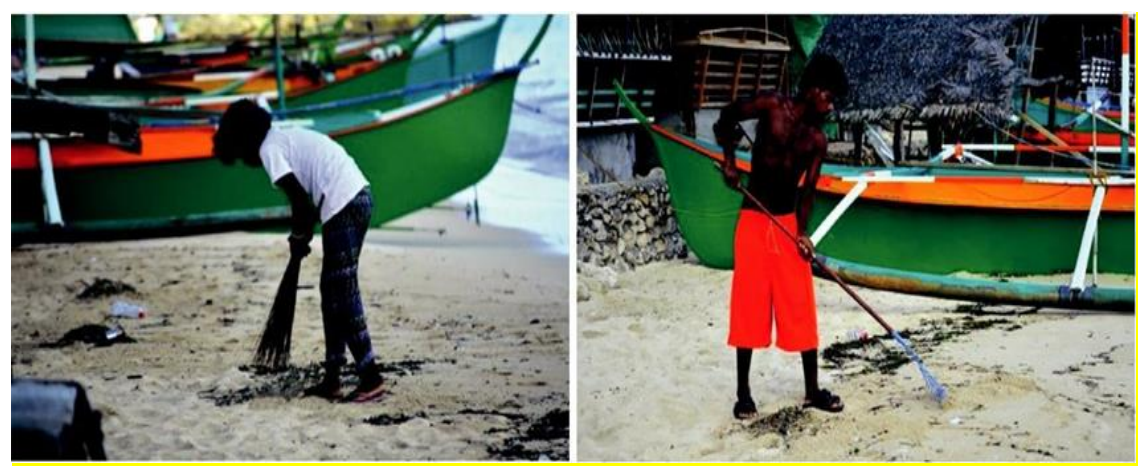
Aetas are industrious people who will not waste time inside their houses; instead, they are ubiquitous finding means to surpass every single day. In their account, some of them are helpers and care takers in business establishments along the stretch of Nangaramoan beach while others continue to search the seas and the forests for whatever it may give them.

\section{Food Practices}

Food is never a problem in their community since they are all industrious. They will not allow especially their children to get hungry during the day. Fish is abundant in a sea near them, and the forest has also assured them a source of food to eat. Just like the ordinary people, rice is the complementary food for their dishes.Rice is accessible to them as a result of barter to labor or other goods to the business owners in Nangaramoan beach.
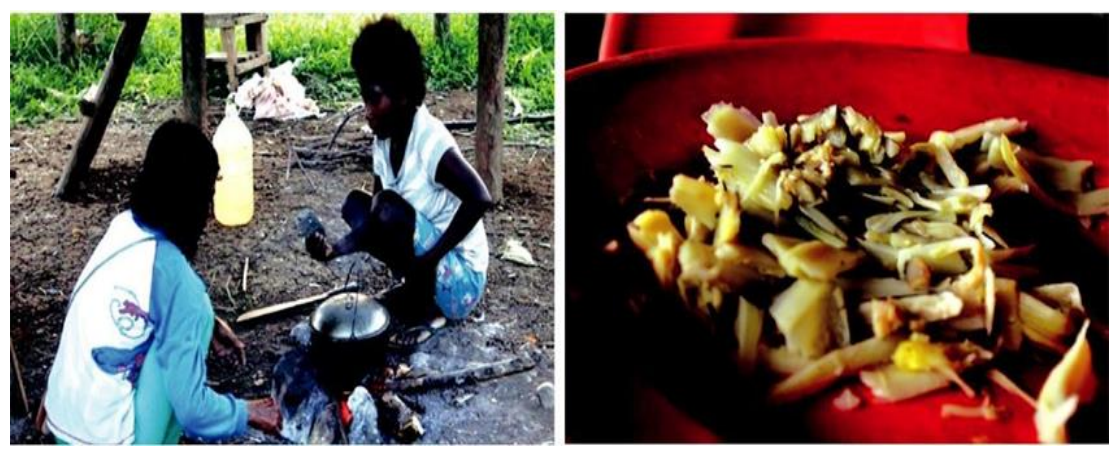

\section{Health and Sanitation}

Theirs is a remote community from the center of Sta. Ana, in effect, health assistance is not adamant. Children of weaker resistance to diseases are more prone to coughs, colds and fever. It is a public knowledge that Aetas mainly rely on herbal medicines to cure diseases and open wounds. Since their group lives near the forest and coastal areas, they are rich in medicinal plants. The big leaves of a tree called -Ditall can cure high fever while - Kutsayll is reputed for curing dry cough. The sea water, in some instances, can also sanitize and heal wounds.

But at the present time, they do not rely only on this indigenous cure. They avail themselves of medical help and medicines at the municipal clinic. They already have growing trust for modern medical help. 
And by distance also, mothers who deliver babies would have their houses as birthing centers. Good to note that there are already a number of pregnant Aeta women whose deliveries are anticipated and brought to hospital early.

Their community is lacking waste disposal facility like water seals. Toiletries as well are things to be introduced for hygienic purposes which will highly protect them from diseases. The community mainly relies in an excavated spring inside the forest for potable water. It produces enough supply of water for the whole community. If it is clean and safe still remains a question. Their spring is an openpit vulnerable to any contamination.

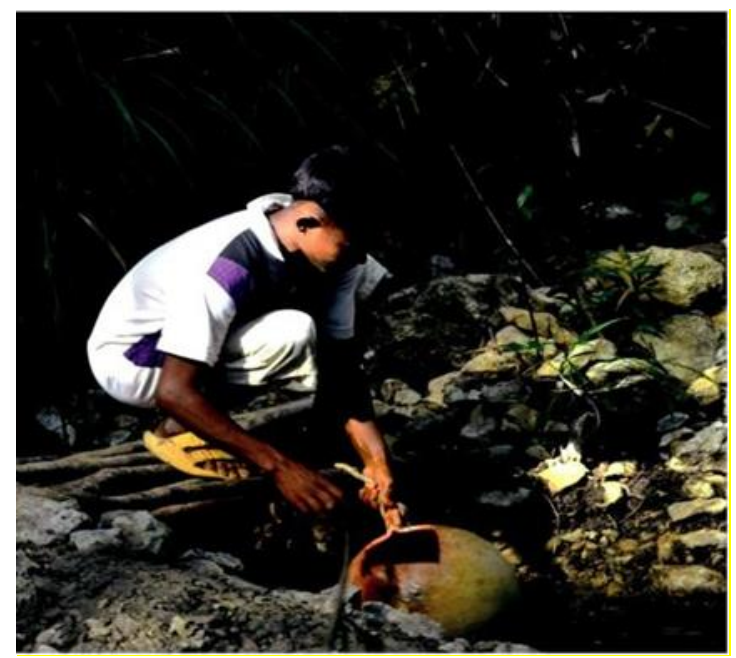

\section{Education}

Due to the distance of their community to the schools in the urban barangays of Sta. Ana, education becomes difficult to achieve for them. According to interviews, graduating in primary and secondary education is already a big achievement for them amidst their less capacity to send children to schools. There are even times when students would get absent for the whole week because of financial predicaments. 
Those who are lucky are enrolled in the Alternative Learning System of the Department of Education. Those who are luckier have graduated high school and are now employed with earnings enough to sustain their primary needs.

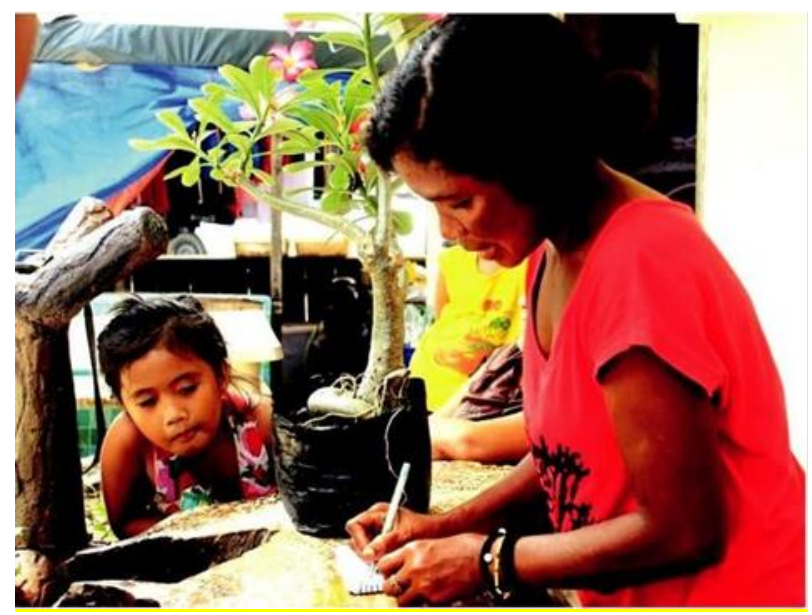

\section{Politics and Government}

The Aetas of Nangaramoan, at the right age, are exercising their right to suffrage. They are good participants of electing public servants, who, at their knowledge, will uplift their lives. Their participation became evident in the recent local and national elections. Some of them already received their voter's identification cards while the restare also encouraged by their seniors to also register after fulfilling the right years of residency and upon the conduct of legal processes to make them official residents and voters of the municipality.

In their setting, they have also their community leader who guides them in their endeavors. They do not practice any kind of election to proclaim whoever will lead them rather; they appoint the eldest one in their group. 


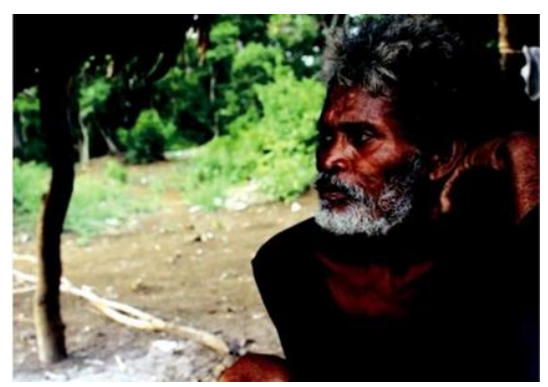

\section{Intermarriages}

These days, Aetas are inevitably influenced by different social factors. This includes inter-marriages that has been evident for the past couples of decades. Aetas who have employed themselves as household helpers in urban areas are married to non-Aeta. This condition is manifested most on female Aetas who work as family maids.

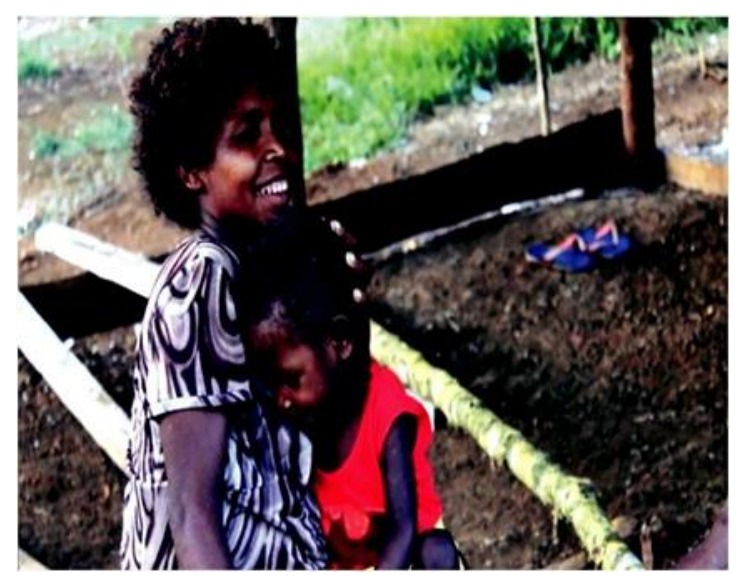

As a result, children with half Aeta blood and half other bloods are produced. This scenario cannot be considered in the community as a threat to their race because there are still those Aetas who marry the same Aetas. 


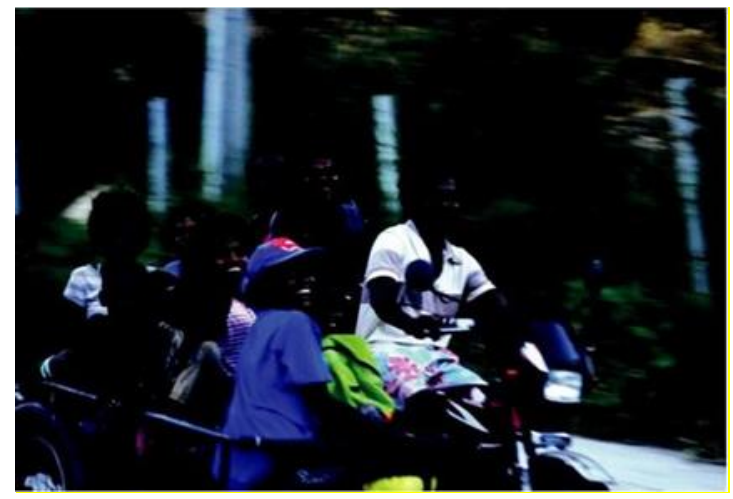

\section{Social and Recreational Activities}

Because they are Aetas doesn't mean they do not have dreams and goals in their life. Many of them have also aspirations in life. There are already Aetas who studied not just in elementary and secondary but also in college and some of them are already professionals.

Despite of their simple living, for them:there is still a room for happiness. They can manage to smile amidst difficulties in life. Poor living is not a hindrance for them to stop dreaming and being happy but a challenge to strive more and work hard in life.

In present settings, the Aetas play with the advancement in technology. As accounted, some of the influences brought by technology are watching in portable DVD's, listening to radios, using of solar panels. Solar panel serves as their source of electricity on their community. Due to lack of money they can't afford to install electricity for them to have a source of light especially in the evening. A certain business man who owns an establishment in Nangaramoan beach introduced the solar panel in exchange of their labor. These activities are in exchange to their tradition of resting together at the foot of the trees, staying inside their houses for siesta, and the like.

\section{Discussion}

This research aims to document the contemporary lifestyle of the Aeta community in Nangaramoan, Sta. Ana, Cagayan. It ferreted out that the Aetas in 
Nangaramoan in Sta. Ana, a municipality reputed to house several enthralling beaches that entice tourist, domestically and internationally, are products of resettlement. Some are offsprings of their forebears who originally owned the land that encompasses the wide of the Nangaramoan beach and later on was sold, while some are natives of Gattaran and Penablanca, Cagayan who have decided to migrate in the place to find greener pasture. In the province's geography, their community is situated in the north-eastern tip facing the direction to the Batanes group of islands in the north and the Pacific Ocean in the east. Their area is a gateway to Pozo Robo (east) and Nangaramoan (north) beach resorts. It is just beside the concrete road constructed at the advent of tourism industry in Sta. Ana. Their group is no different to Aetas around the country. They are still those that have kinky hair, dark skin tone and short in height (Kunard 2004; Harrison 2002; Keller 2008; Munro 2008; Strathman, 2013). Their identity can be traced as familiar to the early settlers in the Philippines, the Borneos. Their group has no idea of the clock-time because they are used todepending on the position of the sun. The sun serves as an only instrument for them to recognize when to commence and end their daily activities (Keller, 2008).

Through photography, it was eyed that the Aetas of Nagaramoan are ubiquitous; finding means to surpass every single day. In their account, some of them are helpers in business establishments along the stretch of Nangaramoan beach while others continue to search the seas for fishes and the forests for orchids to sell. The result implies that, until today, foraging is still one of the main economic activities of the Aetas in order for them to survive their daily needs (Tindowen 2016; McHenry, et. al, 2013; Parungoa, 2011; Bolido, 2000). Their industriousness helps them find food for their families; they exchange goods to rice, while their dishes mainly consist of what the nature could offer them. However, the issue of health is inevitable in the community. Their source of potable water is just an open-pit and so, children are more susceptible to soil-borne diseases. They prefer to use proper medication, however, the Aetas do not have enough income to buy medicines and cannot afford to visit the nearest rural health unit because they prioritize their livelihood. This is why herbal medicines are favorable for them which are much available in their area. The use of herbal medicines is adamant among indigenous people whose communities are situated in remote areas (Strathman, 2013; Ignacimuthu \& Ayyanar, 2006; Muthu, 2006).

In education, there are those children who are enrolled in the Alternative Learning System of the Department of Education. ALS is designed by the DepEd 
to serve as an avenue for the out-of-the-school youth to still learn and get formal education (Tindowen, Bassig, Cagurangan, 2017). Education plays an integral role among indigenous people to conquer ignorance and eventually be at par with the contemporary society (Cronin, 2000). And those who are luckier have graduated high school and are now employed with earnings enough to sustain their primary needs. Among Aetas, education has helped them cope with the fast-changing world. On the other hand, some of the Aetas of Nangaramoan, at the right age, are exercising their right to suffrage or to vote. They are already good participants in electing public servants, who, at their knowledge, will uplift their lives. Based on the Aetas in Nangaramoan, they believe that the government could help them develop their livelihood and other aspects in their lives as well as the preservation of their rich culture and tradition.

Interaction with lowlands or other ethnic tribes has been evident for the past couples of decades. Aetas who have employed themselves as household helpers in urban areas are married to non-Aeta. This condition is manifested mostly on female Aetas who work as family maids. As a result, children with half Aeta blood and half other bloods are borne. Essential studies imply that inter-marriages become evident due to the social interaction of Aetas with other ethnicities (Kim 2010; Strathman, 2013; Santos-Acuin, Gepte, \& Dedace, 1997).

In present settings, the Aetas play with the advancement in technology. As accounted, some of the influences brought by technology are watching in portable DVD's, listening to radios, using cellular phones and the introduction of solar panels. These activities are in exchange to their tradition of resting together at the foot of the trees, staying inside their houses for siesta, and the like. In the study of Hortelano, Juan and Tindowen (2016), games like Sigegud, Magsinaang-uagw and Magkabay were documented and it was found out that these games are for survival and entertainment. Undeniably, their culture is challenged by the birth of technology in their community. This finding is supported by previous studies elaborate on the emergence of technology and the new media (Munro, 2008; Balilia, et. al., 2014). Meanwhile, herbal medicines were used by the old Aetas to cure diseases (Martin, 2013; Anyenam, 1995). The use of herbal medicines can apparently be observed but in minimal conditions. Now, the contemporary medicines are being introduced to them.

In general, the Aetas of Nangaramoan, Sta. Ana, Cagayan still possess indigenous activities. However, some of these are being challenged by the 
influential technology and tribal interaction. Further, several factors greatly affect a certain culture (Keller, 2008; Gaillard, 2007; Balilia, 2013; Acaba, 2008). Technology, for one, could help improve the lives of the indigenous people, but it can also be a curse especially when taken without enough backgrounders and caution. However, the dynamism of their practices is a result of carrying their indigenous way of living in the modern age. Aetas still choose to practice this indigenous activities even in contemporary times and envision passing this culture to the future generations.

As of today, the Aetas of Nangaramoan, Sta. Ana, Cagayan are trying to cope with the period of the growing society wherein they are dynamic about being receptive to how technologies can make their lives even easier and better.

\section{Conclusion}

The contemporary lifestyle of the Aetas of Nangaramoan, Sta. Ana, Cagayan were documented with the use of photography. The advent of technology has, by far, affected their ways of living, however, Aetas still carry their indigenous lifestyle even in contemporary times with the hope that it will be passed to next generation.In the present setting, it was found out in this study that the Aeta culture of Nangaramoan, Sta. Ana, Cagayan is one that is dynamic in the current advancement of technology.

The municipality of Sta. Ana, Cagayan should have an effective development programs with the goal of continuously preserving the indigenous activities of the ethnic community in the place. Photographers and photojournalists are highly encouraged to use pictorial reportage as a medium to promote the different indigenous practices of the indigenous people.

Possible extension of this research will shed light on how else can technology and interaction with other ethnic groups affect the lifestyle and culture of indigenous communities.

\section{Disclosure statement}

No potential conflict of interest was reported by the authors. 


\section{References and notes:}

Acaba, J. P. (2008). The Aeta's relocation and their struggle for survival.

Anyinam, C. (1995). Ecology and ethnomedicine: exploring links between current environmental crisis and indigenous medical practices. Social Science \& Medicine, 40(3), 321-329.

Azarya, V. (2004). Globalization and international tourism in developing countries: Marginality as a commercial commodity. Current Sociology,52(6), 949-967. doi: 10.1177/0011392104046617

Balilla, V. S., Anwar McHenry, J., McHenry, M. P., Parkinson, R. M., \& Banal, D. T. (2013). Indigenous Aeta Magbukún self-identity, sociopolitical structures, and self- determination at the local level in the Philippines. Journal of Anthropology, 2013.

Balilla, V. S., McHenry, J. A., McHenry, M. P., Parkinson, R. M., \& Banal, D. T. (2014). The assimilation of western medicine into a semi-nomadic healthcare system: A case study of the indigenous Aeta Magbukún, Philippines. EcoHealth, 11(3), 372-382..

Bananuka, T., \& John, V. M. (2014). Picturing community development work in Uganda: fostering dialogue through photovoice. Community Development Journal, 50(2), 196- 212. doi: $10.1093 / \mathrm{cdj} / \mathrm{bsu} 036$

Bardis, A. (2004). Digital photography and the question of realism. Journal of Visual Art Practice, 3(3), 209-218.. doi: 10.1386/jvap.3.3.209/0

Bolido, L. B. (2000). Nomadic Aetas [ethnic groups in the Philippines] are now farming. Agriculture (Philippines).

Bolter, J. D., Grusin, R., \& Grusin, R. A. (2000). Remediation: Understanding new mediamit Press.

Bowannie, M. K. (2009). Our People, Our Land, Our Images: International Indigenous Photographers. The American Indian Quarterly, 33(4), 566-568.

Brown, E. H. (2008). The Corporate Eye: Photography and the Rationalization of American Commercial Culture, 1884-1929. JHU Press.

Castleden, H., \& Garvin, T. (2008). Modifying Photovoice for community-based participatory Indigenous research. Social science \& medicine,66(6), 13931405.

Coles-Ritchie, M., Monson, B., \& Moses, C. (2015). Drawing on dynamic local knowledge through student-generated photography. Equity \& Excellence in Education, 48(2), 266-282. .doi: 10.1080/10665684.2015.1025615

Cronin, J. K. L. (2001). Changing perspectives: Photography and First Nations identity.

Cuevas-Wolf, C. (1998). Indigenous cultures, leftist politics and photography in Mexico from 1921 to 1940 .

Dingley, R. (2001). The Unreliable Camera: Photography as Evidence in Mid-Victorian Fiction. Victorian Review, 42-55.

Dyson, L. E. \& Underwood, E. (2006). Indigenous people on the web. Journal of Theoretical and Applied Electronic Commerce Research, 1(1).

Fischer-Olson, A. H. (2014). Imagining the Way Forward Through Museum Space: Approaching Working Relationships Between Museums and Indigenous Communities. University of California, Los Angeles. 
Gaillard, J. C. (2007). Resilience of traditional societies in facing natural hazards. Disaster Prevention and Management: An International Journal,16(4), 522544. doi: 10.1108/09653560710817011

Gigler, E. (2008). Indigenous Australian art photography: an intercultural perspective. Shaker.

Halvaksz, J. (2008). Photographing Spirits: Biangai Photography, Ancestors, and the Environment in Morobe Province, Papua New Guinea.Visual Anthropology, 21(4), 310- 326.

Herr, C. M. (2014). Marketing Native Objects, Visualizing Native Bodies: New Deal Photography and the Sherman Insitute. University of California, Riverside..

Higgins, M. (2014). Rebraiding photovoice: Methodological métissage at the cultural interface. The Australian Journal of Indigenous Education,43(2), 208217..doi: $10.1017 /$ jie.2014.18

Hortelano, R. Juan, J. P. \& Tindowen, D. J. C. (2015). Indigenous games of the Aetas of Penablanca, Cagayan. Bannag: Journal of Local Knowledge, 2(1), 6-17.

Ignacimuthu, S., \& Ayyanar, M. (2006). Ethnobotanical investigations among tribes in Madurai district of Tamil Nadu (India). Journal of Ethnobiology and Ethnomedicine, 2(1), 25.

Jennings, D., \& Lowe, J. (2013). Photovoice: Giving voice to Indigenous youth. Pimatisiwin:

A Journal of Aboriginal and Indigenous Community Health, 11(3), 521-537.

Johnson, T. (1998). Spirit Capture: Photographs from the National Museum of the American Indian. Smithsonian Inst Pr..

Keller, C. M. (2008). Visual Griots: Social, political, and cultural histories in Mali through the photographer's lens. Indiana University.

Ketelle, D. (2010). The ground they walk on: Photography and narrative inquiry. The Qualitative Report, 15(3), 547.

Kim, G. W. (2010). Registering the Real: photography and the emergence of new historic sites in Japan, 1868-1882.

Kunard, A. (2004). Promoting culture through photography in the National Gallery of Canada and the Still Photography Division of the National Film Board of Canada, 2005.

Lavallée, L. F. (2009). Practical application of an Indigenous research framework and two qualitative Indigenous research methods: Sharing circles and Anishnaabe symbol- based reflection. International journal of qualitative methods, 8(1), 21-40. doi: 10.1177/160940690900800103

Lydon, J. (2012). Photography and the Recognition of Indigenous Australians: Framing Aboriginal Prisoners. Australian Historical Studies, 43(2), 210-232. doi: 10.1080/1031461X.2012.662938

Martin, K. J. (2013). Native footprints: Photographs and stories written on the land. Decolonization: Indigeneity, Education \& Society, 2(2).

McHenry, M. P., Anwar-McHenry, J., Balilla, V. S., \& Parkinson, R. M. (2013). The Indigenous Aetas of Bataan, Philippines: Extraordinary genetic origins, modern history and land rights. Singapore Journal of Tropical Geography, 34(3), 292-306. doi: $10.1111 /$ sjtg.12038

Molintas, J. M. (2004). The Philippine indigenous peoples' struggle for land and life: challenging legal texts. Ariz. J. Int'l \& Comp. L., 21, 269.

Munro, J. F. (2008). - Drawn towards the lensll: Representations and Receptions of Photography in Britain, 1839 to 1853. 
Muthu, C., Ayyanar, M., Raja, N., \& Ignacimuthu, S. (2006). Medicinal plants used by traditional healers in Kancheepuram District of Tamil Nadu, India. Journal of Ethnobiology and ethnomedicine, 2(1), 43.

Nickel, D. R. (2001). History of photography: the state of research. The Art Bulletin, $83(3)$,

548-558.doi: 10.1080/00043079.2001.10786996

Ocampo, R., \& Ocampo, R. E. M. A. (2014). The economic life of the negritos of Luna, Apayao. Asia Pacific Journal of Multidisciplinary Research, 2(1).

Parungoa, J. E. V. (2011). Values and the communication of change: The value filters of the nlp communication model applied to Aetas in Loob Bunga Zambales. Journal of Southeast Asian Studies, 16(1).

Sandweiss, M. A. (2004). Print the legend: photography and the American west. Yale University Press.

Santos-Acuin, C., Gepte, A. T., \& Dedace, M. J. (1997). The Philippines: the Aetas of Canawan during wet and dry seasons. Culture, environment, and food to prevent vitamin A deficiency. Boston, Mass, USA: International Nutrition Foundation for Developing Countries, 55-69.

Shots, C. (1998). Photographers, Expeditions, and Collections. Spirit Capture: Photographs from the National Museum of the American Indian, 77-106.

Strathman, N. D. (2013). Through Native Lenses: American Indian Vernacular Photographies and Performances of Memories, 1890-1940. University of California, Los Angeles.

Tindowen, D. J. C. (2016). The Economic Life of the Aetas of Northern Philippines. Khazar Journal of Humanities \& Social Sciences, 19(4).doi: 10.5782/22232621.2016.19.4.97

Tindowen, D. J. C., Bassig, J. M., \& Cagurangan, J. A. (2017). Twenty-First-Century Skills of Alternative Learning System Learners. SAGE Open, 7(3), 2158244017726116.

Todd, A. M. (2003). Environmental sovereignty discourse of the Brazilian Amazon: national politics and the globalization of indigenous resistance. Journal of Communication Inquiry, 27(4), 354-370.

Wright, C. (2004). Material and memory: photography in the Western Solomon Islands. Journal of Material Culture, 9(1), 73-85.

\section{Contact Information}

E-mail: djtindowen2015@gmail.com 